\title{
BLICKDIAGNOSE
}

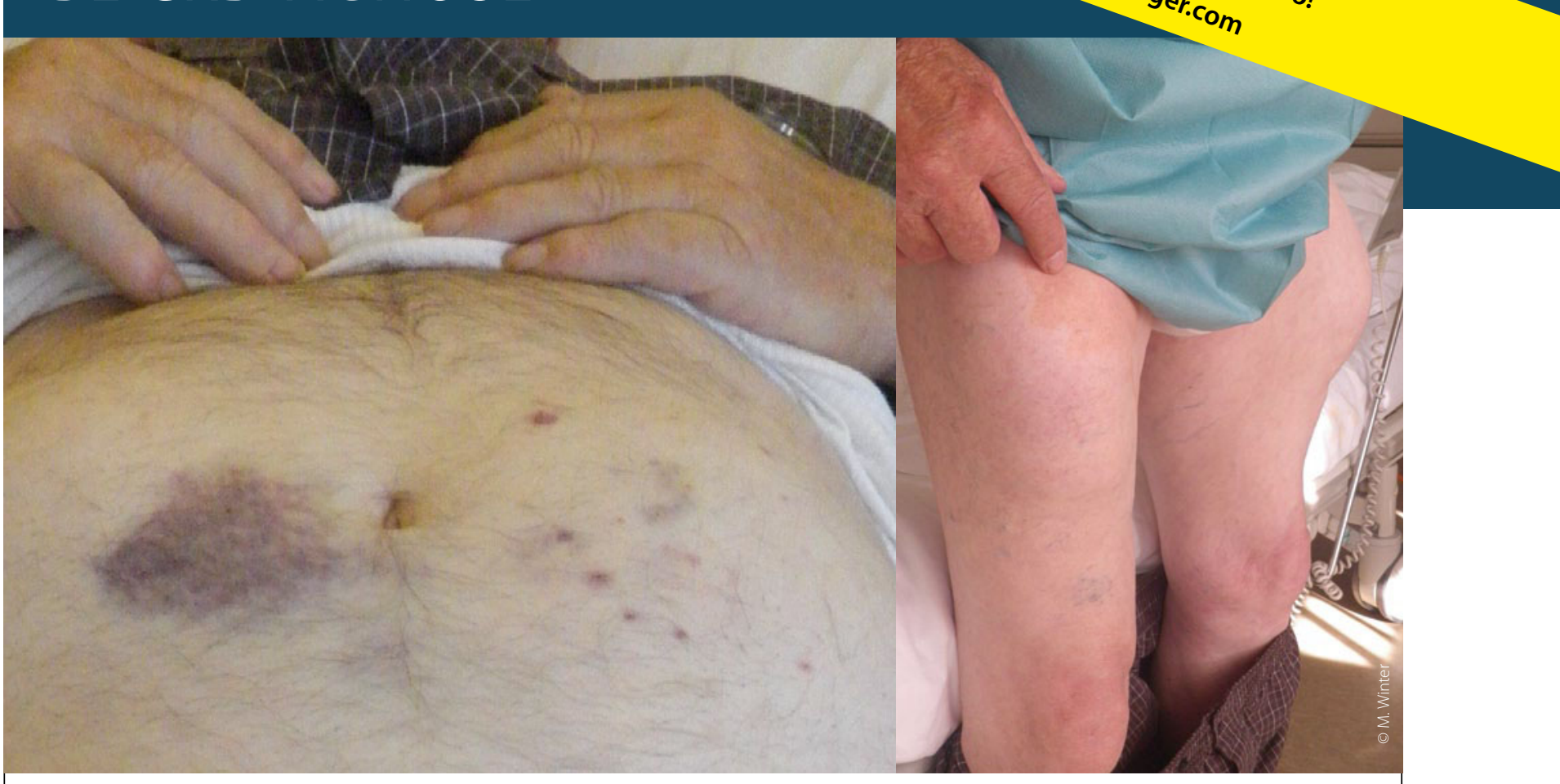

Nach 40 Jahren Insulintherapie

\section{Weiche Tumoren am Mittelbauch und an den Oberschenkeln}

Der 86-jährige Patient wurde von uns wegen eines Nicht-ST-Hebungsinfarktes behandelt. Bei dem Patienten ist seit $\mathbf{4 0}$ Jahren ein insulinpflichtiger Diabetes mellitus Typ 2 bekannt.

- Am lateralen Oberschenkel und lateralen Mittelbauch beidseits fallen inspektorisch und palpatorisch weiche verschiebliche Tumoren auf.

An diesen Stellen hat der Patient sein Insulin s. c. appliziert. Früher habe er Schweine- und Rinderinsulin gespritzt. Jetzt benutzt er humane Insuline. Die Veränderungen haben sich mit der Insulintherapie über Jahre entwickelt.

Es besteht das Bild einer lokalen Lipohypertrophie, einer gutartigen Veränderung als Nebenwirkung der Insulintherapie. Sie tritt häufiger unter tierischen Insulinen auf. Beschwerden machen die Veränderungen dem Patienten nicht.
Neben Verwendung von modernen Insulinen sollte man auf ein systematisches Wechseln der Injektionsstellen achten, um lokale Nebenwirkungen zu vermeiden.

Keywords: diabetes, lipohypertrophy

- Dr. med. Mathias Winter, Klinikum Crailsheim Abt. Innere Medizin, Gartenstraße 21,

D-74564 Crailsheim

\section{Weitere Infos auf}

springermedizin.de

Weitere Fälle unserer Leser finden Sie im Internet unter: - http://www.springermedizin.de/blickdiagnose 